\begin{tabular}{|c|l|}
\hline Title & $\begin{array}{l}\text { Generation of a - A lkylthio Radicals by Photoinduced One Electron Oxidation of a -Stannyl Sulfides and Their Use for } \\
\text { Carbon-Carbon Bond Formation }\end{array}$ \\
\hline Author(s) & Ikeno, Taketo; Harada, Manabu; A rai, Noriyoshi; Narasaka, Koichi \\
\hline Citation & $\begin{array}{l}\text { Chemistry Letters, 26(2), 169-170 } \\
\text { https://doi.org/10.1246/1.1997.169 }\end{array}$ \\
\hline Issue Date & 1997 \\
\hline Doc URL & http://hdl.handle.net/2115/70772 \\
\hline Type & article \\
\hline File Information & cl.1997.169.pdf \\
\hline
\end{tabular}

Instructions for use 


\title{
Generation of $\alpha$-Alkylthio Radicals by Photoinduced One-Electron Oxidation of $\alpha$-Stannyl Sulfides and Their Use for Carbon-Carbon Bond Formation
}

\author{
Taketo Ikeno, Manabu Harada, Noriyoshi Arai, and Koichi Narasaka* \\ Department of Chemistry: Graduate School of Science. The University of Tokyo. 7-3-1. Hongo, Bunkyo-ku. Tokyo 113
}

(Received November 6, 1996)

Cation radicals, generated from $\alpha$-stannyl sulfides by the photoinduced single electron transfer, cleave into $\alpha$-alkylthio radical intermediates with the elimination of the stannyl group. The $\alpha$-alkylthio radicals thus formed are utilized for carboncarbon bond forming reactions.

Though sulfides are easily oxidized to give their cation radicals, these cation radicals have found a limited application to carbon-carbon bond formation due to the localization of cation radical center on the sulfur atom. ${ }^{1}$ Recently, we have studied on the one-electron oxidation of $\alpha$-stannyl and $\alpha$-silyl sulfides with metallic oxidants and it was revealed that cation radicals of $\alpha$ stannyl sulfides more readily cleave into their carbocations and stannyl radical as compared with the silyl derivatives. ${ }^{2}$ For example, the oxidation of 2-stannyl-1,3-dithiane 1a with ammonium hexanitratocerate(IV) (CAN) in the presence of electron-rich olefins such as $\alpha$-siloxystyrene 2 gave the coupling product 3 in $82 \%$ yield, while the reaction of the corresponding silyl derivative $\mathbf{1 b}$ afforded $\mathbf{3}$ in much lower yield.

$$
\overbrace{\mathrm{MR}_{3}}^{\mathrm{S}}
$$<smiles>C=C(O[Na])Pc1ccccc1</smiles>

$1 \mathrm{a} \mathrm{MR}_{3}=\mathrm{SnBu}_{3} \quad 2$

1b $\mathrm{MR}_{3}=\mathrm{SiMe}_{3}$

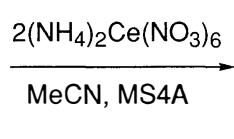

38<smiles>O=C(CC1SCCCS1)c1ccccc1</smiles>

$82 \%, \mathrm{MR}_{3}=\mathrm{SnBu}_{3}$ $18 \%, \mathrm{MR}_{3}=\mathrm{SiMe}_{3}$
Since $\alpha$-alkylthio carbocations are formed from $\alpha$-stannyl sulfides by the oxidation with metallic reagents and are utilized for the $\mathrm{C}-\mathrm{C}$ bond forming reactions, we have examined the photoinduced one-electron oxidation of $\alpha$-stannyl sulfides to carry out the $\mathrm{C}-\mathrm{C}$ bond formation without the metallic oxidants.

A methanol solution of (phenylthiomethyl)tributylstannane (4a) and 5 molar amounts of 2-cyclohexen-1-one (5) in a Pyrex tube was irradiated for $3 \mathrm{~h}$ by a high pressure mercury lamp through UV cut filter $(h v>300 \mathrm{~nm}){ }^{3}$ After the purification by thin layer chromatography (silica gel; hexane : ethyl acetate $=4$ : 1), 3-(phenylthiomethyl)cyclohexan-1-one (6) and 1-phenylthiomethyl-2-cyclohexen-1-ol (7) were isolated in 53\% total yield as a $48: 5$ mixture. (Methylthiomethyl)tributylstannane (4c) and [bis(methylthio)methyl]tributylstannane (4e) also reacted with 5 and gave the coupling products, but the corresponding silyl derivatives $\mathbf{4 b} \mathbf{b}, \mathbf{d}$, and $\mathbf{f}$ gave no or little coupling product even after $20 \mathrm{~h}$ photoirradiation.

We also examined the effect of the alkyl group on the stannyl group. When a trimethylstannyl sulfide $\mathbf{4 g}$ was used instead of the tributylstannyl sulfide $\mathbf{4 a}$, the reaction proceeded faster; however, the yield scarcely increased. Thus the difference of alkyl group is not essential. The results are shown in the following table.
Table 1. Reaction of $\alpha$-stannyl and $\alpha$-silyl sulfides with 2-cyclohexen-1-one

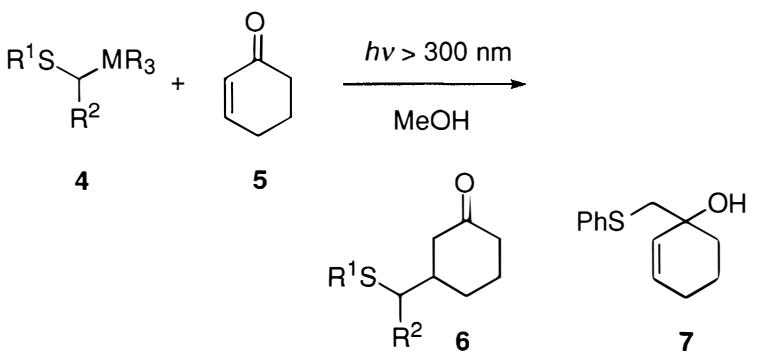

\begin{tabular}{cccccc}
\hline $\mathrm{R}^{1}$ & $\mathrm{R}^{2}$ & & $\mathrm{MR}_{3}$ & $\mathrm{Time} / \mathrm{h}$ & Yield of 6 /\% \\
\hline $\mathrm{Ph}$ & $\mathrm{H}$ & $(\mathbf{4 a})$ & $\mathrm{SnBu}_{3}$ & 3 & 48 a) \\
$\mathrm{Ph}$ & $\mathrm{H}$ & $(\mathbf{4 b})$ & $\mathrm{SiMe}_{3}$ & 20 & 3 \\
$\mathrm{Me}$ & $\mathrm{H}$ & $\mathbf{( 4 c )}$ & $\mathrm{SnBu}_{3}$ & 3 & 50 \\
$\mathrm{Me}$ & $\mathrm{H}$ & $(\mathbf{4 d})$ & $\mathrm{SiMe}_{3}$ & 20 & trace \\
$\mathrm{Me}$ & $\mathrm{MeS}$ & $\mathbf{( 4 e )}$ & $\mathrm{SnBu}_{3}$ & 3 & 41 \\
$\mathrm{Me}$ & $\mathrm{MeS}$ & $(\mathbf{4 f})$ & $\mathrm{SiMe}_{3}$ & 20 & 0 \\
$\mathrm{Ph}$ & $\mathrm{H}$ & $\mathbf{( 4 g )}$ & $\mathrm{SnMe}_{3}$ & 1 & 50 b) \\
\hline
\end{tabular}

a, b) The alcohol 7 was also obtained in $5 \%$ and $7 \%$, respectively.

In the reaction of $\mathbf{4 a}, 1,2$-bis(phenylthio)ethane and thioanisol are obtained in $15 \%$ and $9 \%$ as side products, which were supposed as the coupling and hydrogen-abstracted products of phenylthiomethyl radical. Thus totally about $80 \%$ of the $\alpha$ alkylthio radical was generated in the reaction. To elucidate the mechanism of the reaction, the photoreaction of $\mathbf{4 a}$ and $\mathbf{5}$ was examined in $\mathrm{CH}_{3} \mathrm{OD}$ and $\mathrm{CD}_{3} \mathrm{OD}$. In $\mathrm{CH}_{3} \mathrm{OD}$ and $\mathrm{CD}_{3} \mathrm{OD}$, the coupling product $6 \mathrm{a}$ was deuterized in $77 \%$ and $81 \%$, respectively. And the deuterized position was the 2-position of 6a. Based on the observation, the reaction is considered to proceed as follows; the cation radical species of $\mathbf{4 a}$ is formed by single electron transfer to $\mathbf{5}$ and then cleaves into phenylthiomethyl radical, which reacts with the radical anion of $\mathbf{5}$ to give the anion of $\mathbf{6}$ which is immediately protonated by methanol.

Mariano et al. have reported a similar type of carbon-carbon bond formation between (trimethylsilyl(TMS)methyl)amines and 2-cyclohexen-1-one (5) in the photoinduced electron transfer reaction. ${ }^{4}$ As for the photoinduced one-electron oxidation of $\alpha$ TMS sulfides, there have been reported only the coupling reaction with sensitizers such as 9,10 -anthracenedicarbonitrile, 5 acenaphthylenedione, ${ }^{6}$ and phthalimide. ${ }^{7}$

In the reaction of (phenylthiomethyl)trimethylstannane $(\mathbf{4 g})$ and 4,4-dimethyl-2-cyclohexen-1-one (8), a mixture of the 
adducts 9 and 10, were isolated in $60 \%$ yield in a $1: 1$ ratio. The difference of the product distribution in the addition reactions of 2-cyclohexen-1-one (5) and 4,4-dimethyl-2-cyclohexen-1-one (8) would be due to the steric reason.

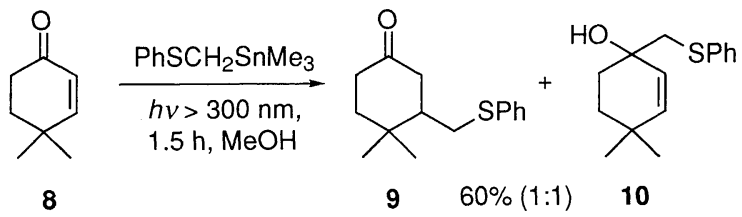

The present radical formation was then applied to intramolecular cyclization reactions. 3-Substituted cyclohexenone derivative $\mathbf{1 1}$ which has a (tributylstannyl)methylthio group in the side chain was directly irradiated $(h v>300 \mathrm{~nm})$ for $3 \mathrm{~h}$ in methanol. The desired spiro compound 12 was, however, obtained in low yield (23\%) along with a methyl sulfide 13 $(60 \%)$ and a dienone $14(5 \%)$. And 11 was directly irradiated in acetonitrile with 5 molar amounts of water instead of methanol, the reaction proceeded much slower and the product 12 was little obtained (5\%) after $20 \mathrm{~h}$ irradiation. On the contrary, when 11 was irradiated in the presence of a 0.3 molar amount of 1,4-naphthalenedicarbonitrile (DCN) as a sensitizer in acetonitrile, the product $\mathbf{1 2}$ was produced in $84 \%$ yield without a detectable amount of $\mathbf{1 3}$ and 14. Thus, by employing the DCN-mediated one-electron oxidation, the intramolecular coupling reaction proceeds smoothly. In acetonitrile with 5 molar amounts of water, photosensitized reaction of $\mathbf{1 1}$ with DCN also gave 12 in $84 \%$ yield. This suggests that a trace amount of water may be proton donor of the reaction.<smiles>CCCCCSCCC1=CC(=O)CCC1</smiles>

11
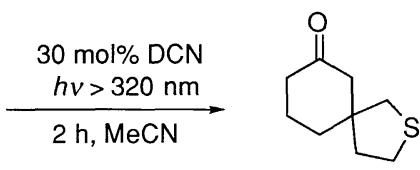

$1284 \%$

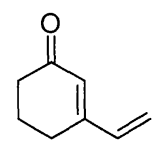

14
The cyclization of the acyclic enone $\mathbf{1 5}$ also did not proceed by the direct irradiation in acetonitrile-methanol, while the product 16 was obtained in $61 \%$ yield by the photoirradiation in the presence of the sensitizer, DCN.<smiles>CCCCCCC(=O)C=CCCSCCc1ccccc1</smiles>

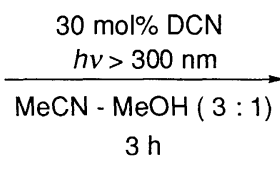

15

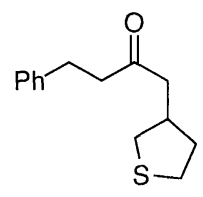

$1661 \%$
Concerning $\alpha$-stannyl and silyl sulfides, Yoshida and Glass reported that the Sn-C $\sigma$-orbital interacts with the sulfur $p$ orbital more than the Si-C $\sigma$-orbital does, because of the higher energy level of Sn-C $\sigma$-orbital than that of Si-C bond. ${ }^{8}$ Accordingly, the cation radical generated on the sulfur atom of $\alpha$-stannyl sulfides is delocalized enough into the $\mathrm{Sn}-\mathrm{C} \sigma$-orbital to accelerate the nucleophilic attack on the stannyl group. ${ }^{9}$

The present photoinduced one-electron oxidation of $\alpha$ stannyl sulfides generates $\alpha$-alkylthio radical intermediates, while the oxidation with metallic oxidants gives $\alpha$-alkylthio carbocations as reported before. ${ }^{2,10}$ Each of the reactive species thus formed reacts with electron-rich and -deficient olefins, respectively. ${ }^{11}$

\section{References and Notes}

1 R. A. Pabon, D. J. Bellville, and N. L. Bauld, J. Am. Chem. Soc., 105, 5158 (1983); K. Narasaka and T. Okauchi, Chem. Lett., 1991, 515.

2 K. Narasaka, T. Okauchi, and N. Arai, Chem. Lett., 1992, 1229; K. Narasaka, N. Arai, and T. Okauchi, Bull. Chem. Soc. Jpn., 66, 2995 (1993).

3 Irradiation was carried out using a Rico-Kagaku Sangyo Co. $400 \mathrm{~W}$ high pressure mercury lamp and Kenko UV-30 filter.

4 U.-C. Yoon, J.-U. Kim, E. Hasegawa, and P. S. Mariano, J. Am. Chem. Soc., 109, 4421 (1987); E. Hasegawa, W. $\mathrm{Xu}$, P. S. Mariano, U.-C. Yoon, and J.-U. Kim, J. Am. Chem. Soc., 110, 8099 (1988).

5 E. Hasegawa, M. A. Brumfield, and P. S. Mariano, J. Org. Chem., 53, 5435 (1988).

6 U.-C. Yoon, Y.-C. Kim, J.-J. Choi, D.-U. Kim, P. S. Mariano, I. S. Cho, and Y.-T. Jeon, J. Org. Chem., 57, 1422 (1992).

7 U.-X. Yoon, H. J. Kim, and P. S. Mariano, Heterocycles, 29, 1041 (1989); U.-C. Yoon, S.-J. Lee, K.-J. Lee, S.-J. Cho, C.-W. Lee, and P. S. Mariano, Bull. Korean. Chem. Soc., 15, 154 (1994).

8 J. Yoshida, J. Synth. Org. Chem. Jpn., 53, 69 (1995); R. S. Glass, A. M. Radspinner, and W. P. Singh, J. Am. Chem. Soc., 114, 4921 (1992).

9 G. Pandey, G. D. Reddy, and G. Kumaraswamy, Tetrahedron, 50, 8185 (1994).

10 The difference of the cation radical fragmentation between metallic oxidation and photoinduced electron transfer oxidation may ascribe to the reaction intermediate. In case of metallic oxidation, the generated cation radical is naked in solvent. On the other hand, the cation radical generated by photoinduced one-electron oxidation is accompanied with counter anion radical in solvent cage.

11 The similar selective C-Si bond cleavage has been reported by Mariano et al. in the single electron transfer photoreaction of (silylmethyl)amines. The photochemical oxidation of (silylmethyl)amines generates aminomethyl radicals by the elimination of the silyl group, while imminium cations are formed from the cation radicals by the oxidation with metallic oxidants. X. Zhang, Y. S. Jung, P. S. Mariano, M. A. Fox, P. S. Martin, and J. Merkert, Tetrahedron Lett., 34, 5239 (1993). 